\title{
Making Transfer Climate Visible: Utilizing Social Network Analysis to Facilitate the Transfer of Training
}

\author{
JOHN-PAUL HATALA \\ PAMELA R. FLEMING \\ Louisiana State University
}

\begin{abstract}
In this article the authors introduce social network analysis (SNA) as a methodology for analyzing transfer climate prior to training. The literature has indicated that transfer climate is critical to a trainee's ability to apply the new knowledge, skills, behaviors, and attitudes they gain through training back to the workplace. SNA serves as a tool for analyzing a participant's organizational network relationships prior to training to help the facilitator, trainee, and supervisor gain an accurate picture of the transfer climate. Based on this analysis, measures can be taken to develop strategies to deal with relational barriers prior to training that will facilitate the participant's transfer of learning back to the work environment. The process of conducting SNA is described and illustrated using a case example. The benefits of using SNA to enhance transfer climate and the implications for further research and practice are discussed.
\end{abstract}

Keywords: transfer climate; transfer of training; social network analysis; relational barriers

More than ever, organizations are attempting to capitalize on training initiatives to move their strategic agendas forward. These initiatives require that the individuals participating in training take new knowledge back to the workplace and apply what they have learned. However, a number of barriers have been identified that impede the successful transfer of training back to the job, such as a nonsupportive organizational environment and the applicability of the training (Kim, 2004;

The authors would like to thank James C. Gumm for his review and comments of the article. Correspondence should be sent to John-Paul Hatala, Louisiana State University, School of Human Resource Education and Workforce Development, 142 Old Forestry Building, Baton Rouge, LA 70803, or by email to jphatala@1su.edu.

Human Resource Development Review Vol. 6, No. 1 March 2007 1-31

DOI: $10.1177 / 1534484306297116$

(C) 2007 Sage Publications 
Machles, 2002; Noe, 1988; Rossett, 1997). As a result of these barriers, it is estimated that between $10 \%$ and $20 \%$ of the training actually transfers to the workplace (Georgenson, 1982). Human Resource Development (HRD) practitioners are often confronted with learning transfer issues that have not demonstrated return on investment for the organization (Rouiller \& Goldstein, 1993). Researchers have attempted to address the barriers to training transfer by exploring the factors related to this complex process (Eagan, Yang, \& Bartlett, 2004; Kontoghiorghes, 2002; Lim, 2001; Lim \& Johnson, 2002). The factors identified have been commonly categorized under trainee characteristics, training designs, and work environment (Baldwin \& Ford, 1988; Holton \& Baldwin, 2000). Although the literature explores a number of potentially important factors contributing to the transfer process, the process has mainly focused on a psychological and individualistic perspective (London \& Flannery, 2004).

This article proposes a methodology for identifying the relational barriers to training transfer by making visible the social structure within the transfer climate. Through the use of social network analysis (SNA), the authors posit that defining the social structure prior to the delivery of training will provide the opportunity to assess transfer climate and address any relational barriers that may affect the transfer of training to the workplace. SNA has been identified as a useful method for analyzing network properties within an organizational context and is presented as a means for delineating the relationships within the work environment where transfer is to take place (Hatala, 2006). Research on organization, supervisory, and peer support has been linked to successful transfer (Cromwell \& Kolb, 2004; London \& Flannery, 2004). However, the authors are unaware of any literature that has specifically examined the network structure of an organization as a variable affecting transfer climate. Researchers have advocated the design and development of transfer needs assessments to facilitate the transfer of training (Goldstein, 1986; Lim \& Morris, 2006). The importance of facilitating the transfer process before, during, and after the training intervention is paramount to training transfer taking place. This article will add to the training transfer literature by proposing SNA as a methodology for assessing the relational dynamics within the transfer climate prior to, during, or after training has been delivered.

Therefore, the purpose of this article is to illustrate how SNA can be used to make visible the social structure in which the transfer of training is to take place. More specifically, by exploring the social network aspects of transfer climate prior to a training intervention, action can be taken to address the environment in which the participant will transfer new knowledge and help maintain transfer behavior by managing relationships that support the transfer. This action includes exploring the relationship of the training participant and the individuals they interact with on the job (i.e., cohorts, supervisor, manager). If it is determined that transfer is at risk, measures can be taken to address these issues and develop strategies to increase the likelihood of transfer occurring. The article has three objectives: 
1. To conduct a review of the literature on transfer climate and existing methods for addressing transfer of training.

2. To introduce SNA as a methodology for making transfer climate visible by uncovering the relationships that may inhibit or facilitate successful training transfer.

3. To discuss future directions for using SNA as a methodology for testing transfer climate hypotheses.

\section{Methodology}

An integrative literature review of transfer climate and social networks was conducted through a search of the EBSCO Host's Academic Search Primer, Ingenta, ERIC, Proquest, and JSTOR databases. The key words used in the literature search included transfer climate, learning transfer, barriers to learning transfer, transfer of training, overcoming transfer barriers, social network theory, and SNA. The following questions were explored:

1. How transfer climate affects transfer of training?

2. How various types of social support affect training transfer?

3. What methods are used to overcome transfer barriers?

4. How can SNA be utilized as a methodology to measure organizational, peer, and supervisory support?

5. What future directions for the field of HRD can be drawn from the literature?

As a result, three bodies of literature were reviewed: management, HRD, and psychology. The HRD literature was used as the foundation for transfer of training theory and addressed Questions 1, 2, and 3, whereas psychology and management literature were drawn on as examples of fields that support the theories addressed in Questions 1, 2, and 3. The focus of the literature review was intended to identify the social dynamics within transfer climate and how it affects training transfer. Additionally, this literature review sought to define social barriers to training transfer and to determine whether SNA could serve as a method to identify and overcome these barriers, answering Question 4. Future directions for HRD were generated from this research addressing Question 5.

\section{Transfer of Training}

From a theoretical perspective, transfer of training occurs when prior knowledge and/or skills affect the way in which new knowledge and skills are learned and executed (Taylor, 2000, p. 4). Broad and Newstrom (1992) identified training transfer as a "transfer partnership" consisting of three key members - the trainee, the trainer, and the manager or supervisor. The compilation of these major players is pivotal to the success of transfer of training. With consistently changing job environments and job requirements, learning transfer has become a major concern. This section presents models and frameworks that serve as the foundation for various strategies fostering the training 
transfer process and specifically examines the work environment as a major element in carrying out transfer.

Baldwin and Ford's (1988) theoretical framework examined training transfer and stated that the transfer process consists of three components: training input factors, training outcomes, and conditions to transfer. The conditions to transfer are predicated on generalizing training to the job in addition to maintaining learned skills over time on the job. The framework also looks at organizational climate factors including peer and supervisory support as having a dramatic effect on the whether transfer of knowledge has the opportunity to occur. Holton's (1996) conceptual model focused on three primary training outcome interventions: learning, individual performance, and organizational results. More specifically, performance outcome involves the motivation to transfer, the design of training, and transfer climate (environment), where transfer climate focuses on peer and supervisory support as major factors to the transfer process. Holton (1996) recognizes that to promote positive transfer behaviors, the need for continued research on the evaluation of training transfer is crucial.

\section{Organizational Climate and Transfer Climate}

Organizational climate refers to the current perceptions of people within a work environment with regard to the observable (social, political, and physical) nature of the personal relationships that affect the accomplishment of work within a particular organization (Denison, 1996). One of the distinguishing characteristics of an organization's climate, as opposed to its culture, is the transitory and malleable nature of an organizational member's perceptions (Denison, 1996). In other words, the perceived relational dynamics that exist within an organization influence the climate, and because the study of organizational climate only captures a "snapshot" of an organization at one point in time change can and will likely occur without notice (Litwin \& Stringer, 1968). Continued study of a particular organization as its climate changes can lead to a better understanding of the relational patterns that exist within an organization. This understanding can then be used to explain the organizational climate variables that remain distinct or converge (Lim \& Morris, 2006).

An important subset of these perceptions of organizational climate relates to the transfer of training, also known as the transfer climate of an organization (Lim $\&$ Morris, 2006). These perceptions have unique properties that influence an individual's motivation and behavior toward the transfer of training (Baldwin \& Ford, 1988). More specifically, the transfer climate encompasses an individual's perceptions of supervisor support, opportunity to use new training, level of peer support, supervisor sanctions, and positive or negative personal outcomes resulting from application of training on the job (Holton, Bates \& Seyler, 1997). Researchers have used the term transfer climate to describe an individual's perception of the social support structure that exists within an organization (Cheng $\&$ Ho, 2001). This social support structure manifests itself in the form of peer, 
supervisory, and organizational support. Transferring new knowledge and skills back to the workplace requires a commitment not only from the employee but also from the organization. This research indicates that transfer of trained tasks back to the workplace goes far beyond the quality of the training program and the delivery method and is in large part dependent on the transfer climate of an organization (Campbell, 1988).

Rouiller and Goldstein (1993) explored the issue of organizational transfer climate by conducting an empirical study that evaluated the relationship between climate and posttraining behavioral change. They defined transfer climate as consisting of two types of workplace cues: situation and consequence cues. They identified four types of situation cues: goal cues, social cues, task cues, and selfcontrol cues. The consequence cues included positive reinforcement, negative reinforcement, punishment, and no feedback. Their research findings indicated that organizational transfer climate was significantly related to the transfer behaviors of a trainee and that learning and organizational transfer climate accounted for a significant portion of the variance in learning transfer among those in the workplace. The authors suggested interventions based on an organization's transfer climate as a tool for facilitating training transfer back to the workplace. By linking Rouiller and Goldstein's transfer climate dimensions to specific individuals within an organizational network, practical intervention strategies can be developed to make the climate more conducive to training transfer.

\section{Relational Barriers to Training Transfer}

Often during and after training sessions, participants are excited about the new knowledge; they ask questions, clarify points, and even input value-added observations that spark stimulating dialogue. Unfortunately, this excitement is all too often limited to the training environment (Rossett, 1997), and even though an initial excitement toward the training may be present, its impact on transfer may be reduced if relational barriers exist. Relational barriers to transfer of learning can be traced to a nonsupportive organizational climate because of the lack of peer and supervisory support. Research has shown that without supervisory, peer, and organizational support, these barriers will dissuade training transfer behaviors (Cromwell \& Kolb, 2004; Lim \& Morris, 2006; Taylor, 2000). More important, relational barriers may cause participants to feel that skills acquired during training are perceived by others as having little value, thereby giving participants little to no incentive to transfer the learned skills back to the job (Kim, 2004).

Holton, Bates, and Seyler (1997) defined supervisor support as the extent to which supervisors support and reinforce the use of learning on the job. According to Machles (2002), managers may not have the knowledge to support the information employees have learned, meaning higher level managers, without the benefit of experience and training, may not themselves fully comprehend the importance of assisting in transfer of training, thus creating a barrier to transfer. 
This lack of understanding most likely contributes to management's lack of commitment and strengthens the supervisor support variable as a critical influence on successful transfer (Lim \& Morris, 2006). Additionally, Cromwell and Kolb (2004) cited organizational climate and the lack of supervisory and peer support as barriers to training transfer, and the degree of support given once the trainee returns to the workplace greatly influences whether or not transfer takes place.

Training transfer is enhanced by involving supervisors and trainees in the needs assessment phase of training development (Hatala \& Gumm, 2006; Machles, 2002). This allows managers and trainees to provide their input, thereby increasing the likelihood of their support toward the training intervention. This support from both management and individual organizational members will aid in creating a positive transfer climate because both sides will perceive the training as worthwhile and meeting the needs of themselves and the organization. However, to accomplish this, an understanding of the relational dynamics within the work group must be understood; otherwise, the opportunity to leverage the key influencers within the group may be limited. Also, by encouraging goal setting and self-management, learners will demonstrate a higher level of transfer (Gist, Bavetta, \& Stevens, 1990) in that they will feel a stronger connection to the overall objective of the training.

The next section will examine the process of conducting an SNA to uncover the hidden relational barriers within a transfer climate. SNA will assist in the identification of relational barriers and how they affect training transfer.

\section{The Network Approach}

Social network theory explains the interpersonal mechanisms and social structures that exist among interacting units (i.e., small groups, large groups, departments, units, within organizations, between organizations) (Wasserman \& Faust, 1994). More specifically, it is the study of how the relationships of a person, group, or organization affect beliefs or behaviors. The theory relates to a number of different levels of analysis that can be used to determine the interaction between individuals and their environment. The term network typically refers to a set of objects or nodes, and the mapping of the interaction and relationships between the objects (Wasserman \& Faust, 1994). Social network theory refers to the objects as people or groups of people. By measuring the interactivity of individuals through mapping relationships, researchers can uncover the specific dynamics that exist between and within groups. Social capital is one example why social network theory is studied. By understanding the mappings connecting individuals to a set of others, we stand to learn much about how individuals utilize their connections to achieve desired outcomes (Coleman, 1988). From an organizational context, actors within the network can increase performance or move upward based on the connections they possess. In addition, the level of social capital helps to determine how 
individuals use their position within a network to accumulate power in social settings (Burt, 1997).

Some of the formal theoretical properties in the network perspective include centrality (betweenness, closeness, degree), position (structural), strength of ties (strong/weak, weighted/discrete), cohesion (groups, cliques), and division (structural holes, partition) (Scott, 2000; Wasserman \& Faust, 1994). These represent the building blocks for developing and conceptualizing network theory (White, 1997).

\section{SNA}

SNA is a method that can provide an empirical measure of an organization's work environment by focusing on the relationships between people while using attribute characteristics (Scott, 2000; Wasserman \& Faust, 1994). These relationships include the feelings people have for one another, the exchange of information, and issues of power. By mapping these relationships, SNA helps to uncover the informal communication patterns to compare them with existing formal structures in hope of explaining various organizational phenomena. More specifically, the position of an individual within the social structure of an organization helps to explain their exposure to and control over information based on the relationships that exist (Burt, 1992). Also, because the pattern of relationships brings individuals into contact with attitudes and behaviors of other members of the organization, these relationships may uncover the attitudes individuals may have toward certain job-related issues (Feeley \& Barnett, 1996; Ibarra \& Andrews, 1993; Meyer, 1994). By uncovering relational information, SNA can be very useful for studying transfer climate.

The SNA approach provides formal definitions of the structural elements that exist within networks (i.e., actors, subgroup of actors, or groups) and can help to identify support relationships that may exist within the work environment. This unique approach provides insight into the dynamics of the interaction between actors and the formation of observable patterns of information exchange between network members that may lead to successful transfer (Hatala, 2006). The ability to measure relationships will help define the transfer behaviors that exist and the impact they might have on the capability of transferring training to the workplace.

Wasserman and Faust (1994) identified some basic assumptions to the network perspective. They include (a) actors and their actions are viewed as interdependent rather than independent, autonomous units; (b) relational ties (linkages) between actors are channels for transfer or "flow" of resources (either material or nonmaterial); (c) network models focus on how individuals view the structural environment of a network as providing opportunities for or constraints on individual action; and (d) network models conceptualize structure (social, economic, political, and so forth) as lasting patterns of relations among actors. The main focus of SNA remains on the interactional component. Attribute data such as age, gender, and race can be collected as well and 
can provide profiles of network members. For a detailed review of the literature on SNA, see Hatala (2006).

SNA represents an assessment method in which practitioners can examine the existing network structure prior to, during, or after a training intervention. In general, social network theory explains the mechanisms and structures that exist within any given environment (i.e., small groups, large groups, departments, units, within organizations). Social network theory can help to explain the impact relations have on training transfer by observing the social structure and the relations that exist within that structure.

\section{Making Transfer Climate Visible}

The literature has strongly supported the need for organization, supervisory, and peer support if transfer of training back to the workplace is to take place (Baldwin \& Ford, 1988; Bates, Holton, Seyler, \& Carvalho, 2000; Clark, Dobbins, \& Ladd, 1993; Cromwell \& Kolb, 2004; London \& Flannery, 2004; Pidd, 2004). Removing barriers that affect successful transfer of training may require changes to the relationships existing within a department, unit, or division. However, for relational change to occur, it is important to understand the dynamics that exist between the environment and the individuals participating in the training program prior to initiating any training intervention. SNA can make transfer climate visible by uncovering the network structure the learners are situated in, which will allow management and individual organizational members to anticipate any barriers to transfer prior to commencement of training. SNA also identifies the flow of information from a formal and informal power situation (Cross \& Parker, 2004; Ibarra \& Andrews, 1993). Network maps enable the visualization of relationships and make what are normally invisible relational dynamics inside a group visible. One of the gaps on transfer training identified in the literature was that many studies focused on the individualistic standpoint (London \& Flannery, 2004). SNA can provide a holistic view by highlighting the relationships related to transfer climate. The SNA approach investigates the organizational properties of relations between and within groups rather than simply the properties of the groups themselves. Transfer of training will be limited if relational patterns are not in keeping with successful application of new learning on the job.

Connectivity is occurring at every level of the organization structure. It cannot be taken for granted that just because a manager requires an employee to attend training transfer will occur. Competing forces are at play from both the formal and informal organization power structure (Hatala \& Gumm, 2006; Torenvlied \& Velner, 1998). At the formal level, these forces take the form of individual perception that management does not support the new learning and therefore has no incentive to implement the new knowledge they have acquired 
through training. Highly central employees to the social environment can be found at the informal level who may not buy-in to the training initiative and as a result not support the objectives of the program. If these forces are not known prior to the development of a training intervention, there is little likelihood of transferring what is learned.

One important element of transfer climate is the level of social support from both supervisors and peers that exists within an organizational unit (Baldwin \& Ford, 1988; Cheng \& Ho, 2001; Cromwell \& Kolb, 2004; London \& Flannery, 2004). The social network perspective views individuals within a network as interdependent, rather than independent and autonomous, units, which is critical to the transfer of training back to the workplace (Wasserman $\&$ Faust, 1994). The relational ties between individuals are channels for transfer of information. If relational barriers are present within a work group, it is likely that application of learning will be blocked by the lack of support from supervisors and coworkers.

The next section will examine the use of SNA as a methodology for illuminating the transfer climate within an organization. For the purposes of guiding the reader through the SNA process, we consider the case of a researcher who wishes to examine the nature of information sharing and job support among coworkers in a small sales department prior to new product training. Because of the nature of the product they sell, formal product training is an ongoing activity within the department. The 14 actors in this case include a sales manager, a supervisor, two senior sales representatives, and 10 sales representatives.

\section{Conducting the SNA}

The following steps outlined by Hatala (2006) provide a general overview of the SNA process (see Table 1). Each step of SNA is explained, followed by an illustration using the sales group case.

\section{Determining the Type of Analysis}

There are two types of analyses that can be conducted; the first is an ego network analysis and the second is a complete network analysis (Scott, 2000; Wasserman \& Faust, 1994). The ego network analysis focuses on a particular individual and is structured around eliciting information about the people he or she interacts with, and about the relationships with those people. This form of analysis should be chosen for individuals who are participating in a training program in isolation to their organization, department, or coworkers. The complete network analysis is concerned with all the relationships among a set of respondents (i.e., entire organization, complete work group), which includes managers, supervisors, and individual organizational members. 
TABLE I: Eight Steps to Conducting a Social Network Analysis

1. Determining the type of analysis

2. Defining the relationships within the network

3. Collecting network data

4. Measuring the relationships

5. Including actor attribute information in the analysis

6. Analyzing the network data

7. Creating descriptive indices of social structure

8. Presenting the network data

SOURCE: Adapted from Hatala, 2006.

\section{Sales Group}

The sample case (sales group) in this article requires that a complete network analysis be conducted as the primary goal is to assess information sharing and job support among the complete group. Additionally, because all members of the work group will be attending the training, complete network analysis is the most appropriate for this situation.

\section{Defining the Relationships Within the Network}

Once the type of network analysis has been established, the relations that will be measured are determined by the objective of the project. Examples of the type of relations that can be measured might include communication relations (e.g., who speaks to whom), instrumental relations (e.g., who asks whom for help), power relations (e.g., who follows whom in informal groups), and interpersonal relations (e.g., who likes who) (Hatala, 2006). The researcher may be interested in determining which relationships reveal information-sharing potential, rigidity in the network, or well-being and supportiveness in the network (Cross \& Parker, 2004).

\section{Sales Group}

In the case of the sales group, the goal is to determine whether relationships are present that promote information sharing and job support as well as to identify the network members who are sought after for company gossip. The intention of the analysis is to assess whether there is the likelihood of transfer occurring after new product training. Cromwell and Kolb (2004) found that those trainees who reported a higher level of support in the work environment were more likely to transfer their newly acquired skills and knowledge to their job. Exploring the relationships will uncover the overall structure and transfer climate within the network and help explain how individuals presently support one another in applying new learning to their work environment. Additionally, 
TABLE 2: Sample Questions for Social Network Analysis Surveys for Transfer Climate

Who do you talk to at least once per week?

To do your job well, who must you depend on?

To do their job well, who generally depends on you?

Who would be useful to interact with more than you do now?

Who do you typically discuss new ideas you've learned from training with?

Who do you turn to after you return from training if you are not sure of something you have learned?

Who do you share new ideas with on how to perform your job function better?

Who generally is not open to new ideas when it comes to performing their job?

Who do you go to for company gossip in your work group?

How often do you talk with following people regarding making changes to the work process?

Who do you typically turn to for help in implementing a new job technique or skill?

How effective is each person listed below in helping you conduct your job?

Who provides feedback on how you are applying what you've learned in training on the job?

Who provides feedback on how well you are performing your job?

Who provides advice to you on how to perform your job better?

Who typically will help you improve your performance if it is not what it should be?

Who do you speak with on how to improve your performance?

Who do you turn to when you need clarification or advice on something you learned from training?

identifying network members who provide gossip may be as important as finding out which members are sought after for job-related information (Cross \& Parker, 2004). If gossip is negatively directed to the organization, it can have a greater impact on employees transferring what they have learned from training back to the job. Informal information flow occurs regularly throughout an organization and can easily be misidentified as formal communications by employees (Kahn, Cross, \& Parker, 2003). Formal and informal organizational communications must be monitored to ensure that information is accurate; otherwise the perceptions of individuals may be altered, ultimately affecting the climate. By defining the relationships prior to the actual training intervention, measures can be taken to make any corrective action required to build a supportive transfer climate.

\section{Collecting Network Data}

Based on the research questions or objective of the project, the data collection technique must fall in line with the appropriateness of the training situation (i.e., amount of time to collect data, amount of time allotted for training 
program, amount of preparation time, type of training). In some instances, collection techniques can include all, or some, of the following: observation, interviews, surveys, or archival documents (Scott, 2000). Table 2 represents some examples of the types of questions that can be asked of participants for social network research on transfer climate. It is recommended that two to four questions are used and are closely linked to the goals and objectives of the intended project (Cross \& Parker, 2004).

\section{Sales Group}

In the case of the sales group, the two questions selected for analysis were: Who do you turn to after you return from training if you are not sure of something you have learned? and Who do you go to for company gossip in your work group? The selection of these two questions was determined after consultation with management and geared specifically toward the product training. The first question was used to address individuals were key points of contact and provided follow-up support to training interventions. The second question was intended to determine which individuals provided the latest information on company news (i.e., company direction, new product allocation, budgets). The managers felt that if the individuals identified as central to the network for new training reinforcement were also "go-to" people for the latest news on company gossip, the message being delivered might be diluted based on their perception of the present status of the company. Therefore, the managers felt strongly that those members who were sought after for new knowledge reinforcement and company gossip could cause the most damage if they were at all misinformed.

\section{Measuring the Relationships}

Determining how the relationships will be measured is the next step of the SNA process. If the objective of the analysis is to simply determine whether a relationship exists between network members, binary measures can be employed by using a " 0 " or a " 1 ." The lack of a relationship between two actors is indicated by a " 0 " and the existence of a relationship is indicated by a "1" (Wasserman \& Faust, 1994). Table 3 presents an example of a survey where the respondents indicated whether a relationship existed with the listed individuals. This type of survey would be administered to a group that works together on a regular basis (complete network) and is attending the same training intervention, which applies specifically to our sample sales group. The goal of this data collection is to identify who the participant is connected to, based on the question proposed.

However, if the strength of the relationship has to be identified, a valued measure would help determine the extent to which the participant interacts with another individual. For example, a Likert-type scale can be used to determine how often an individual shares new knowledge with others in their work 

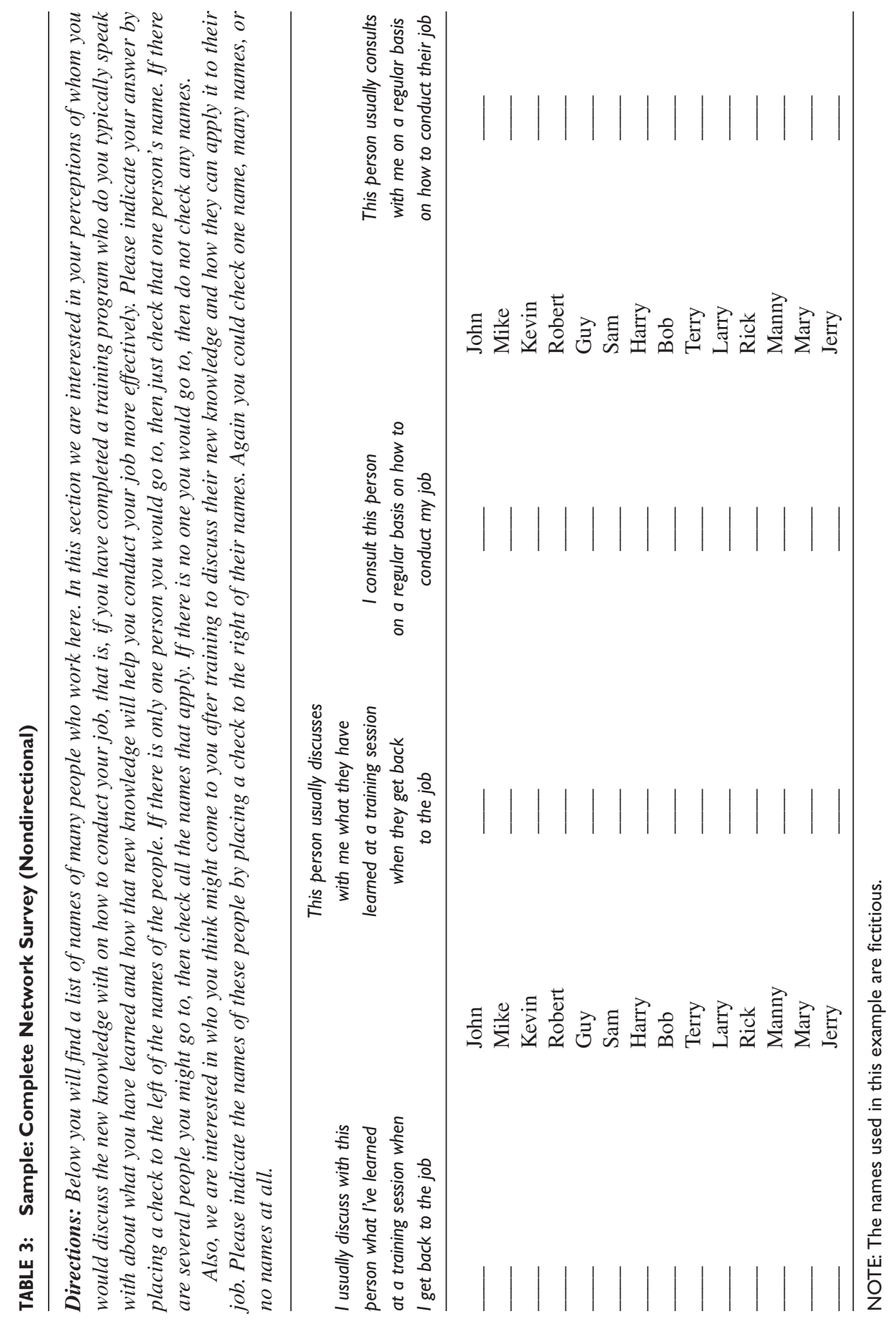


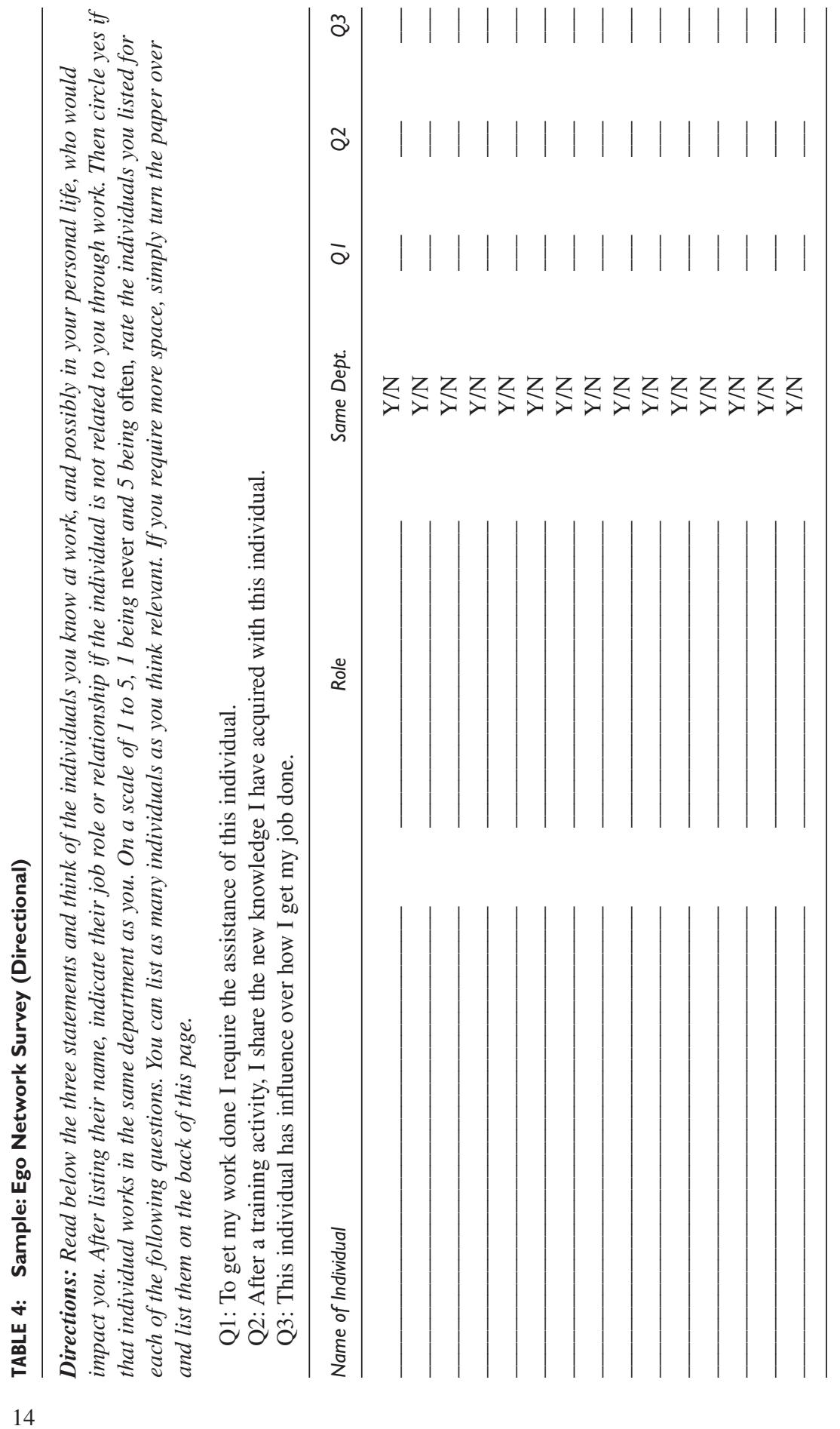


group (i.e., 1 = seldom and $5=$ very often) (see Table 4 ). This type of survey requires that the respondents assess their relationship with the individuals listed and can help determine the extent to which information is exchanged between network members. This survey would be administered to individuals who are participating in a training intervention outside their department or organization on their own (ego network analysis).

\section{Sales Group}

In the case of the sales group, the goal is to identify the frequency of connectivity between network members by using a valued scale. Those actors who were sought after on a frequent basis could be viewed as critical influencers of the transfer climate and addressed accordingly.

\section{Including Actor Attribute Information in the Analysis}

In addition to relational data, attribute characteristics of participants can be collected to help determine unique similarities in groups of individuals (Brass \& Labianca, 1999). For example, if a complete network analysis is conducted, relational ties that demonstrate similar attribute characteristics (i.e., high performers) can be identified to help predict whether transfer will be supported among participants and their supervisors. Other variables may include previous training exposure, educational profile, attitudes toward training, and importance of training to job function. By including attribute information in the analysis, network transfer models can be constructed to help explain why transfer takes place in one work group but not in another.

\section{Sales Group}

Performance history could be collected for the sales group example to ensure that those individuals identified as central to the network were providing information that was in keeping with the department's objectives.

\section{Analyzing the Network Data}

Once the relational and attribute data have been collected, analyzing the data is the next stage of the process. The data and network maps created for this article were generated by UCINET 6, which offers the researcher the ability to compute network measures (Borgatti, Everett, \& Freeman, 2002) as well as to generate network maps through its incorporated visualization software NetDraw (Borgatti, 2002) included in the package. Depending on whether formal research is being conducted or whether practitioners are attempting to discern the network landscape of an individual or group, the analysis is guided by the research question. For example, if the question posed to the sales group 


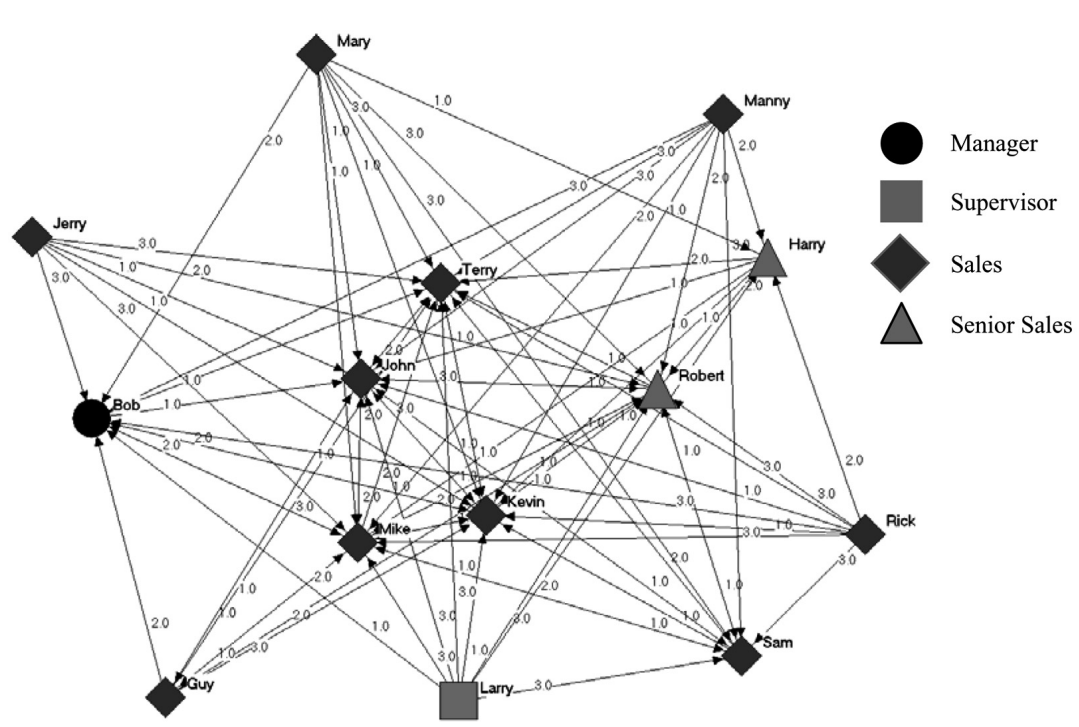

FIGURE I: Directional and Valued Ties; Question: Who do you turn to after you return from training if you are not sure of something you have learned? NOTE: The names used in this example are fictitious.

participants was, Who do you turn to after you return from training if you are not sure of something you have learned? and participants were asked to rate their connection to the individuals within their work group on a scale of 1 (seldom) and 3 (very often), the network map created would comprise directional ties that are valued. In Figure 1, we can see that the strength of the relationship is indicated by the number over the line connecting the network members.

\section{Sales Group}

For example, Rick, a sales representative, shares new knowledge with Robert, a senior sales representative, "very often" (3), but Robert does not share at all with Rick (this is indicated by absence of an arrowed line from Robert to Rick).

If the goal of the analysis is to determine whether a relationship exists, it can be represented by a 0 or 1 . This form of measurement may be useful if the goal of the analysis is to determine whether there is connectivity among work groups. However, this measure is nondirectional and is conducted to determine whether a relationship exists between two individuals, regardless of who initiates the connection. If determining the strength of a relationship is not important, the question posed is geared to identifying a relationship among actors. The 


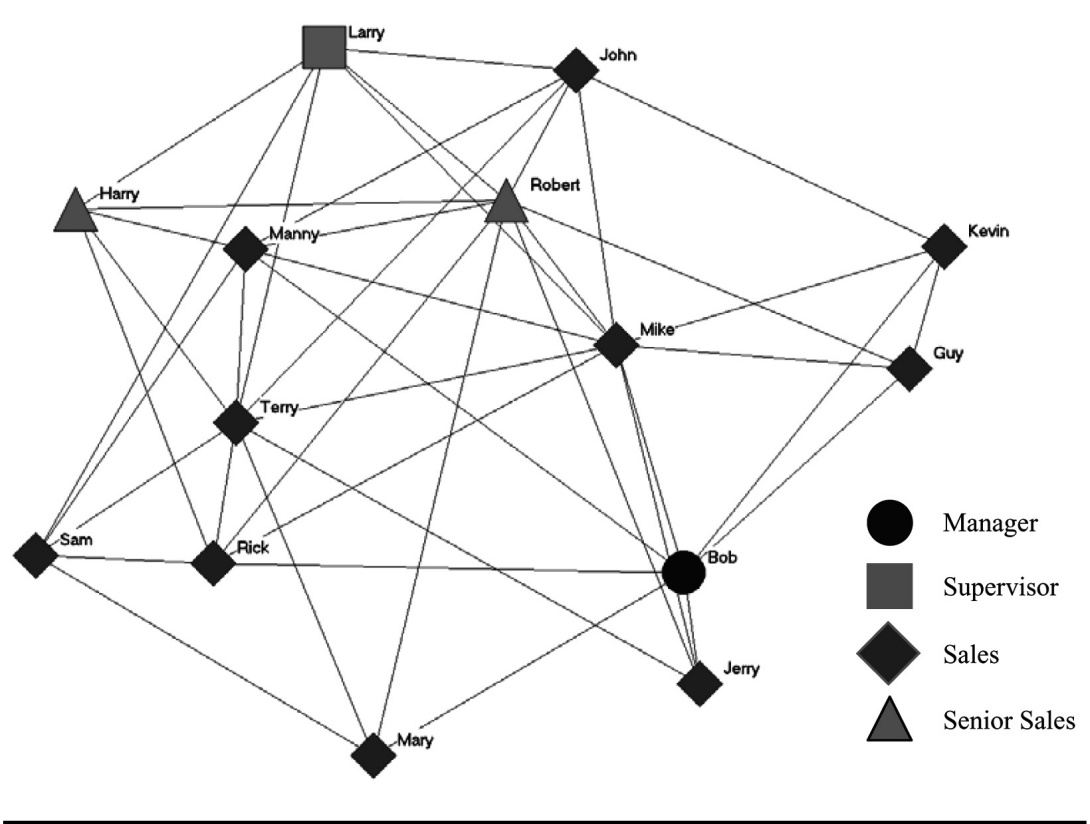

FIGURE 2: Nondirectional Ties

NOTE: The names used in this example are fictitious.

example used for the sales group, Who do you turn to after you return from training if you are not sure of something you have learned? is represented by the existence or nonexistence of a line between actors (see Figure 2).

\section{Creating Descriptive Indices of Social Structure}

Once the data have been collected, the creation of descriptive indices can take place. The descriptive indices of social structure are measures of centrality, density, and cliques. Illuminating the transfer climate will depend on the questions used for the analysis.

\section{Centrality Measures}

If the goal of the analysis is to determine which member is the most sought after for clarifying information learned in a training session, centrality measures can be computed to identify those individuals who clarify or reinforce the training information to the work group on a regular basis. "Betweenness" centrality measures how often a given actor sits "between" others, with "between" referring to the shortest path (Scott, 2000). An actor that is between many actors is assumed to have a higher likelihood of being able to control 
TABLE 5: Individual Centrality Measures

\begin{tabular}{lc}
\hline Employee & Betweeness \\
\hline Question-Who do you go to for advice on performing your job? & \\
John & 8.333 \\
Mike & 7.000 \\
Kevin & 4.000 \\
Robert & 4.000 \\
Guy & 0.667 \\
Sam & 0.000 \\
Harry & 0.000 \\
Bob & 0.000 \\
Terry & 0.000 \\
Larry & 0.000 \\
Rick & 0.000 \\
Manny & 0.000 \\
Mary & 0.000 \\
Jerry & 0.000 \\
Question-Who do you go to for company gossip in your work group? & \\
John & 19.167 \\
Robert & 7.000 \\
Mike & 5.167 \\
Guy & 1.333 \\
Bob & 0.333 \\
Kevin & 0.000 \\
Harry & 0.000 \\
Sam & 0.000 \\
Larry & 0.000 \\
Rick & 0.000 \\
Manny & 0.000 \\
Mary & 0.000 \\
Jerry & 0.000 \\
\hline
\end{tabular}

NOTE: The names used in this example are fictitious.

information flow in the network. If there are only a few members who control information flow within the group, the climate may be negatively oriented toward transfer. Table 5 lists the centrality betweenness measures for the sales group found in Figure 1.

\section{Sales Group}

John possesses the highest centrality measure (8.33) and is in a position to control the flow of information within the group, whether positive or negative. 


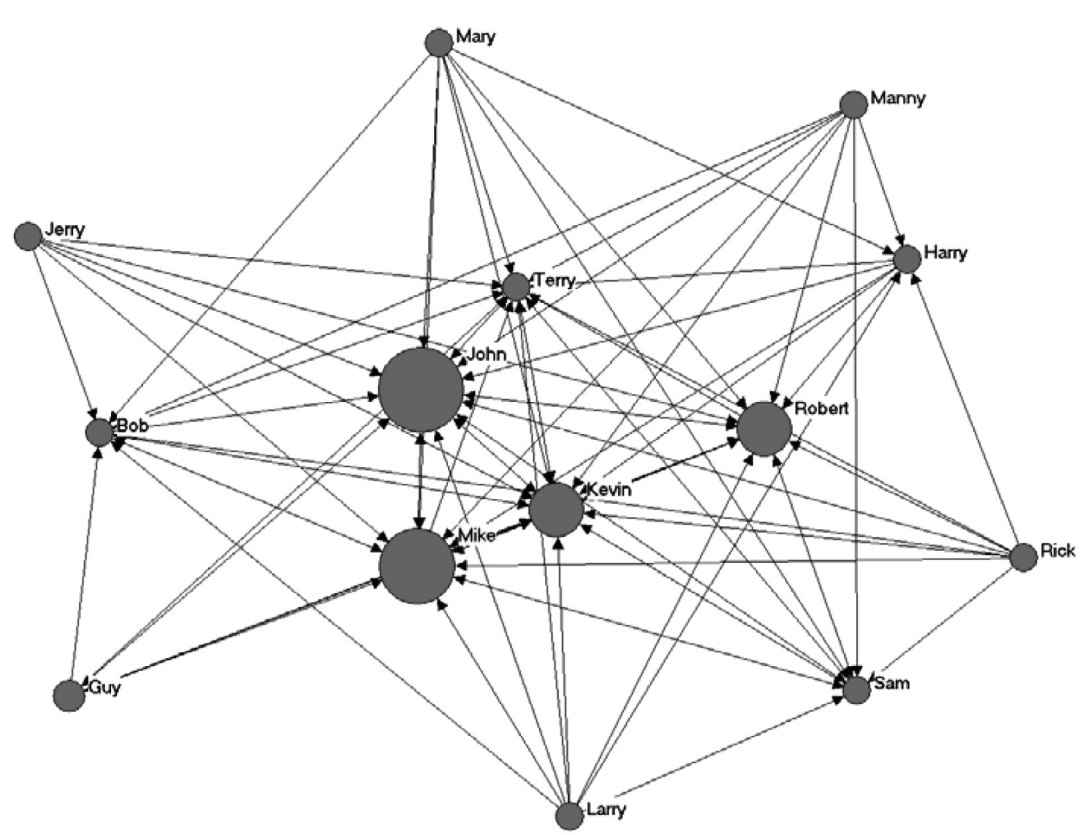

FIGURE 3: Centrality-Betweeness; Question: Who do you turn to after you return from training if you are not sure of something you have learned? NOTE: The names used in this example are fictitious.

In addition, Mike (7.00), Kevin (7.00), and Robert (4.00) are central to the network. John, Mike, and Kevin are sales representatives, whereas Robert is a senior sales representative. This raises questions as to why the sales manager (Bob), supervisor (Larry), and the other senior sales representative (Harry) are not central to the network based on their positions. Even if these individuals supported the training, their influence on transfer may be limited as they are not sought out for information on a regular basis. In addition to displaying the centrality measures, a visual representation of the network structure is displayed in Figure 3 (central actors John, Mike, Kevin, and Robert are displayed as larger circles in the network map).

Now that the central actors have been identified, actions may be taken to support the transfer of training. Those individuals identified as central to the network can help reinforce the goals and objectives of the training to the rest of the group. However, it is imperative that the central actor's perception and understanding of the purpose of the training is in keeping with its desired outcome. Uncovering those individuals who act as brokers of information for group members can help ensure that everyone acknowledges the applicability 
of the new learning. Prior to the training intervention, the trainer could meet with the individuals to discuss the content that will be presented during the training. Therefore, there would be five goals when meeting with John, Mike, Kevin, and Robert: (a) to discuss why training is needed, (b) to solicit input on what content should be delivered during the session, (c) decide on the best way to deliver the training, (d) how to best apply the new learning back to the workplace, and (e) ensure that they will support the transfer of new learning back to the workplace. If the new learning is in keeping with the central actors' existing approach to their job, it is most likely that the new knowledge would be reinforced when network members seek out their advice. However, if the information contradicts the actors approach to performing their job function or if they feel that the new learning is irrelevant to increased performance, transfer of training is less likely to occur. By uncovering the network structure and identifying the central actors, the trainer can take steps to ensure that these individuals will support training transfer to the workplace.

The questions that guide the analysis are situational in nature and should be treated as such when deciphering the data. The central network members may change based on the type of question that is posed to the participants. For example, Figure 3 highlights the central actors for the question, Who do you turn to after you return from training if you are not sure of something you have learned? If the question were changed to, Who do you go to for company gossip in your work group? the central figures may differ as a result of the new question (Figure 4). This is illustrated in Figures 3 and 4; John is highly central in both situations, as well as Robert and Mike, whereas Kevin is no longer central to the network for company gossip (Figure 4). An actor who is sought after for advice on how to transfer new learning to the job and company gossip may make the transfer climate highly volatile and may require further exploration prior to the training intervention. Even if the highly central network member is in line with the training objectives but is misinformed about some negative company information, the transfer of training may not be supported. Uncovering this information prior to the training interventions may be the difference between a successful program and limited intervention effects.

\section{Density Measure}

For transfer to occur, the transfer climate must support the employees when they return to the job. Organizational social support has often been used to represent transfer climate (Cheng \& Ho, 2001). If the question posed through SNA involves the identification of existing relationships that support training transfer, the researcher would want to determine the existing cohesiveness between network members. Measuring for network density will help quantify the cohesiveness that exists within the work group or between groups. Density 
is the number of actual links proportionate to the total possible links that can exist and is calculated using the following equation:

$$
\frac{l}{n(n-1) / 2}
$$

where $l$ represents the number of lines present and $n$ represents the number of nodes within the network. The value of the density measure can range from 0 to 1 , where 1 represents complete density within the network (Scott, 2000).

\section{Sales Group}

For example, the density for the sales group (see Figure 2) for the question, Who do you turn to after you return from training if you are not sure of something you have learned? is .247 , meaning that the actual number of ties in the network is $24.7 \%$ out of the potential number of ties. For the sales group, a density level of $24.7 \%$ problematic in that the connectivity between individuals regarding new information sharing is minimal and may reflect the work climate. If the intervention were to include team building training, it is imperative that what occurs within the training environment follows to the workplace. Measuring the groups' density prior to the training and after will help determine whether the intervention has had any impact on opening communication channels between members. If low-density measures are identified prior to training, content can be geared to addressing specific issues and individuals identified through the analysis. In addition, interviews can be conducted before the training to establish how group members perceive the overall connectivity between members. If common issues are identified, action can be taken prior to the commencement of the training to deal with problems associated with low connectivity, thereby maximizing the opportunity for a higher level of transfer. Benchmarking density measures over time will help determine the most appropriate density level for the particular work group. Periodically measuring the density of the group will help ensure that the transfer climate is at the right level for training transfer to take place.

\section{Cliques}

To determine whether pockets of cohesion exist among network members, the $n$-clique measure can be calculated to identify cliques within the network by setting the desired level of connectedness between actors. Uncovering existing cliques can help explain why certain groups within the network structure are either "for" or "against" the adoption of new learning. For the $n$-clique procedure, $n$ is the maximum path length at which members of the clique will be regarded as connected (Scott, 2000). For example, if the researcher was attempting to identify connected groups of 3 , he or she would employ a 2clique measure, which refers to an actor who is either tied directly or indirectly 


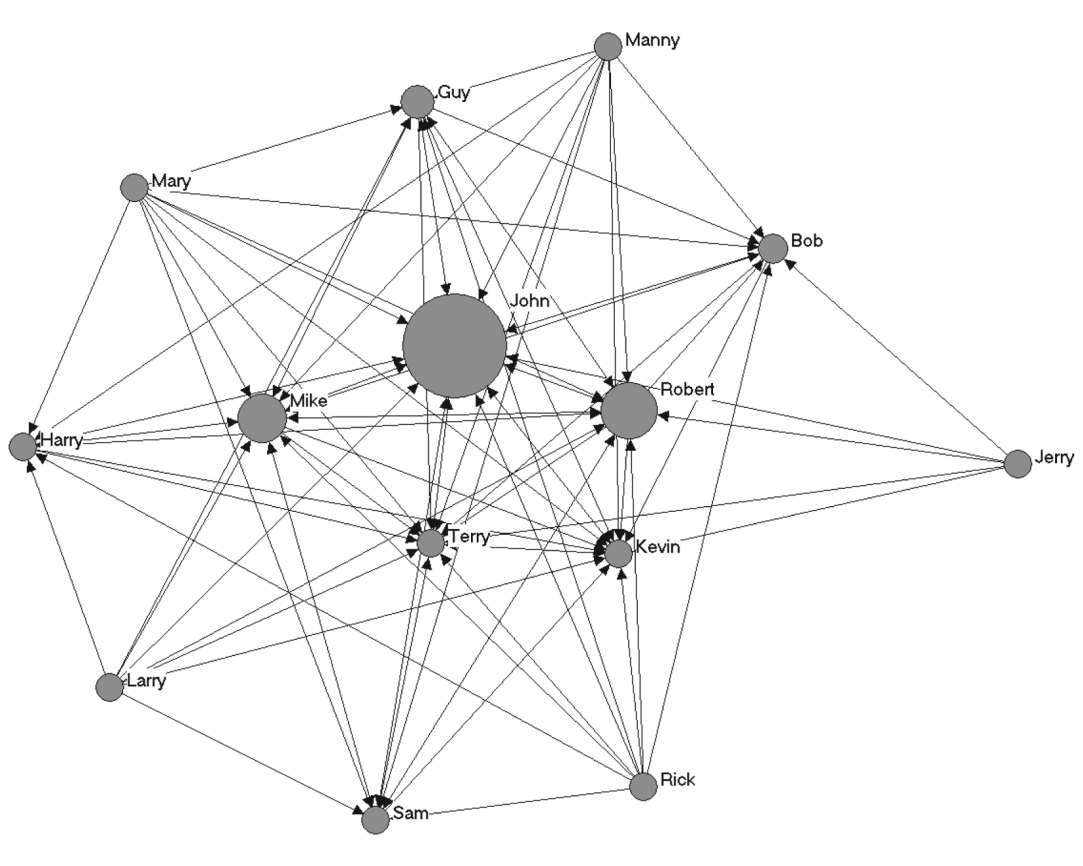

FIGURE 4: Centrality-Betweeness Question: Who do you go to for company gossip in your work group?

NOTE: The names used in this example are fictitious.

to another actor. Those actors identified through the 2-clique measure are situated within a maximum of 2 degrees of separation; therefore, Actor 1 knows Actor 2 directly but may go through Actor 2 to get to Actor 3. In some organizational climates, subgroups may be the norm that can be disruptive to others in a training setting. If these cliques are identified prior to training, it is possible to determine whether there are similarities in performance levels so that precautions can be taken to diffuse or encourage participation in the training situation and transfer back to the job.

\section{Presenting the Network Data}

There are two forms that network data can take, matrix data or sociograms (network map). The matrix data (see Table 6) represent raw data whereas the sociogram (see Figure 1 as an example) provides a visual representation of the connections within a network. From a practical perspective, a sociogram provides organizations the opportunity to visually identify the social structure that exists within their work groups, whereas matrix data provide detailed 
TABLE 6: Valued Data Presented in a Matrix Format

\begin{tabular}{llllllllllllllll}
\hline & Robert & Sam & Guy & Harry & John & Kevin & Mike & Bob & Terry & Larry & Rick & Manny & Mary Jerry \\
\hline Robert & 0 & 1 & 1 & 0 & 1 & 1 & 1 & 0 & 1 & 0 & 0 & 0 & 0 & 0 \\
Sam & 1 & 0 & 0 & 0 & 1 & 1 & 1 & 0 & 2 & 0 & 0 & 0 & 0 & 0 \\
Guy & 2 & 0 & 0 & 0 & 1 & 3 & 1 & 2 & 1 & 0 & 0 & 0 & 0 & 0 \\
Harry & 2 & 0 & 0 & 0 & 1 & 1 & 1 & 0 & 2 & 0 & 0 & 0 & 0 & 0 \\
John & 3 & 1 & 1 & 0 & 0 & 3 & 2 & 0 & 2 & 0 & 0 & 0 & 0 & 0 \\
Kevin & 1 & 0 & 0 & 0 & 1 & 0 & 1 & 1 & 1 & 0 & 0 & 0 & 0 & 0 \\
Mike & 2 & 1 & 2 & 0 & 2 & 2 & 0 & 3 & 2 & 0 & 0 & 0 & 0 & 0 \\
Bob & 0 & 0 & 0 & 0 & 1 & 2 & 2 & 0 & 1 & 0 & 0 & 0 & 0 & 0 \\
Terry & 0 & 0 & 0 & 0 & 1 & 1 & 0 & 0 & 0 & 0 & 0 & 0 & 0 & 0 \\
Larry & 3 & 3 & 0 & 2 & 3 & 1 & 3 & 1 & 3 & 0 & 0 & 0 & 0 & 0 \\
Rick & 3 & 3 & 0 & 2 & 1 & 1 & 3 & 3 & 3 & 0 & 0 & 0 & 0 & 0 \\
Manny & 2 & 3 & 0 & 2 & 3 & 1 & 2 & 3 & 3 & 0 & 0 & 0 & 0 & 0 \\
Mary & 3 & 3 & 0 & 1 & 1 & 1 & 1 & 2 & 3 & 0 & 0 & 0 & 0 & 0 \\
Jerry & 2 & 0 & 0 & 0 & 1 & 1 & 3 & 3 & 3 & 0 & 0 & 0 & 0 & 0 \\
\hline
\end{tabular}

measures of interconnectivity between network members. Sharing this information with both trainees and management will assist in starting a dialogue about the relationships that exist and how they influence the organizational climate. Developing an action plan that deals with the social barriers can ensure that training is supported by managers and coworkers and is transferred back to the job. The network data can be presented at the beginning of a training situation so that participants become aware of the hidden pressures that exist within their working groups. If an entire work group is participating in training, a portion of the training can be dedicated to overcoming the potential barriers to using new learning. For more detail on network measures presented in this section, please see Wasserman and Faust (1994).

\section{Discussion}

SNA can serve as a methodology for identifying the relational patterns that help form the transfer climate by illuminating the network structure of an organization. The example of the sales group provided in this article entailed a complete network analysis. However, in many training situations, participants attend in isolation of other work group members. In this case, ego network analysis can be performed to determine the relational barriers that may affect their ability to transfer new knowledge back to the workplace. The researcher may choose to examine their relationships not only with coworkers but also with those individuals outside the workplace who may have some influence on training transfer (i.e., suppliers, customers, competing firms) (see Table 4). 
Even though the ego analysis only takes into account the relationships from the perspective of the trainee, these perceptions are useful in determining the likelihood for transfer taking place and can be utilized by the trainee and supervisor to reinforce the importance of applying the new learning on the job. If relationships with key influencers (i.e., team leader, supervisor, manager) are considered poor, steps may be taken to explore transfer strategies to deal with strengthening the trainee's interaction with these individuals so that the new learning can be applied on their return to the job. This can easily be incorporated into the training program and followed up with once the program has been completed. In addition, supervisors can be made aware of the importance of encouraging a climate that supports the implementation of new and creative ideas once the employee has returned to the workplace (Clark et al., 1993).

SNA can also serve as an assessment tool prior to the planning of a training intervention to identify who the true "opinion leaders" within the organizational climate are and to include them in the development and implementation of the training program. In addition, these "opinion leaders" can be utilized during and after the training to reinforce the new learning. Increasing the likelihood of training transfer can be accomplished at the design phase of the HRD intervention (Hatala \& Gumm, 2006). Getting buy-in from centrally positioned actors in the network on the training content, delivery mechanism, and overall objective of the training program is an important element of success that is often overlooked; SNA can help to identify these central actors. Employees participating in training are more likely to utilize the new learning if they perceive it as clearly relevant to work-related activities and are supported by their peers. Including individuals who are sought out by other network members will help ensure that the input is representative of the work group and the transfer climate is supportive.

SNA will help add to our knowledge about training transfer by providing the vehicle for mapping out the social structure of an organization that will allow for the identification of relational barriers affecting the transfer climate. Once these barriers are identified, research can start to examine the process of how transfer takes place and how transfer behaviors are maintained over time.

\section{Implications for Further Research}

SNA can be used by the researcher to make the transfer climate visible by uncovering the relational barriers existing within the social structure of a work group that influence the perceptions of network members. This can be accomplished by identifying key employees who are in a position to influence training transfer. Training transfer researchers have much to gain by learning why individuals act and respond to social pressures that exist within the organizational climate. Transfer climate network models can help to identify the hidden influencers who positively or negatively affect the organizational climate. 
Possible research questions include what level of connectedness (density) is required for a work group to transfer training back to the job? How do small cliques within the larger work environment impact transfer of training? Are informal or formal peer support groups more conducive to training transfer? Or are informal organizational power structures (centrality) more influential on training transfer than formal lines of authority? These research questions can be guided by SNA for building and adding to existing training transfer theory.

The majority of transfer literature has focused on the individualistic perspective of training transfer (London \& Flannery, 2004). Only recently have researchers begun to examine organizational support as a facilitating variable to increasing the likelihood that transfer will occur (Cromwell \& Kolb, 2004; London \& Flannery, 2004). More specifically, SNA is supported by the findings of Tracey, Tannenbaum, and Kavanagh (1995) on self-selected work groups, which suggest that interventions that target supervisors, coworkers, and individuals who interact with trainees may yield the greatest dividends. Transfer research is needed to examine the relationships existing within an organization's social structure prior to training interventions to understand the most effective relational patterns that promote a positive transfer climate.

It is also imperative that future transfer research take a holistic approach by collecting both attribute and relational data when examining transfer behaviors. Baldwin and Ford (1988) stated that the number of correlational studies examining transfer climate was problematic in that causality could not be inferred in many of the studies on transfer research. SNA can address this issue by examining the relations within a work group and how central actors influence the application of new learning to the job. SNA can help expose both the positive and negative relationships that either support or hinder transfer efforts. Network models can help to conceptualize transfer climate as lasting patterns of relations among actors and add to training transfer theory building by measuring the impact central actors have on supporting transfer (Hatala, 2006).

In addition, Baldwin and Ford (1998) identified the criterion problem in that the majority of studies conducted on environmental characteristics were typically self-reports of behavioral change as a major measure of transfer. In addition, Cromwell and Kolb (2004) addressed the issue of transfer behaviors over time by examining the sustainability of training behavior over various intervals. They found that training behaviors were not greatly exhibited until the 1-year point. They provide possible reasons for the delay in transfer, which included the lack of time and energy for transfer, the workload, promotional opportunities, or salary incentives. Future studies on training transfer at various intervals may consider using SNA as a means to measure transfer and its effect on social structure over time. Although individual network members may change, the goal of achieving role-specific relational patterns between 
organizational positions will remain constant. Therefore, the goal of analysis may be to determine whether the relational patterns (i.e., workers seek out supervisors for training support) are consistent over time.

For example, the sales manager (Bob) in the sales group case was not sought after for new learning reinforcement at the time of the initial SNA (pretest) based on the question, Who do you turn to after you return from training if you are not sure of something you have learned? If a second SNA (posttest) were to be conducted some time in the future after conscious efforts were made to improve the manager's ability to provide support to his workers, the desired results of the analysis would identify the position as central to the network. Even if the manager were to be replaced by the time the next analysis was conducted, the desired outcome would be the identification of the same relational pattern where the supervisor is sought out for support. Conversely, if an individual was identified in the pretest as a central actor but left the organization by the posttest, the relational patterns could still be examined to determine the impact the individual had on the group and overall supportive nature of the transfer climate itself.

Research has attempted to address the question of network changes over time and has demonstrated that supportive ties are the most likely to persist and that frequent contact between network members is also associated with the persistence of relationships (Feld, 1997; Morgan, Neal, \& Carder, 1996; Suitor \& Keeton, 1997; Wellman, Wong, Tindall, \& Nazer, 1997). In light of this evidence, further research on developing a cohesive social structure that supports training transfer is needed. It would be expected that once a supportive network has been established, and the transfer climate is more positive, training transfer will most likely increase. This can take the form of peer support networks that continue to meet after the completion of training to reinforce transfer to the job.

Projects using SNA should be careful not to generalize network structure based on the question presented. The sales group analysis that was based on two different questions is an example of the situational nature of SNA. An employee who is popular and central to the network but who is not sought after for advice on how to implement new learning on the job can still yield some influence. The influence of this individual may at times outweigh those employees who are sought after for job advice and should not be taken lightly. Buy-in to training programs should come from both the identified subject matter experts and those who are deemed popular from the social perspective. This is a critical component to network analysis and questions should be thought out carefully and in line with theoretical assumptions of the research. Training climate has focused on work environment and has identified organization, supervisory, and peer support as critical factors to successful transfer (Cromwell \& Kolb, 2004; London \& Flannery, 2004). It is important to keep these factors in mind when forming research questions about transfer climate. Aligning trainee attributes to relational data will help uncover the social pressures that exist within a given environment and help to explain why transfer occurs. 


\section{Implications for Human Resource Development Practice}

SNA can also be used by the practitioner to make the transfer climate visible. The use of SNA from a practical perspective is not a complex process and can easily be built into a training program. As was mentioned earlier in the article, there are two types of network analysis-ego and complete network analysis. If the training situation deals with a number of participants from different work groups, units, or organizations, the goal of the SNA should be to explore the relational patterns within their work environment so that when they return to the workplace they can develop a strategy with their supervisors for dealing with any relational barriers identified. Because each individual will be conducting an ego network analysis a number of questions can be asked. The examples provided in Table 2 can be used as a guideline for selecting questions for the analysis. A discussion on the importance of training transfer can be conducted at the beginning of a training session, at which time the SNA can be administered. Each participant fills out the SNA survey and separately ranks each of their network members based on their influence within the group (see Table 6). Small groups can be formed to discuss the findings and answer questions regarding the transfer climate within their own organizations. Examples may include questions such as which of the individuals listed have you labeled a 4 or 5 and why? Which individuals have you labeled as a 3 or lower and why? How important is support from those individuals who you listed as a 4 or 5 ? Relational barriers to transfer can be explored using the participants' key influencers identified through the SNA and strategies can be discussed on how to seek the support needed to apply their new learning on the job. In addition, the participants can be instructed to share their SNA with their supervisor to discuss the most effective ways of implementing the new training at the workplace.

The complete network analysis (sales group example) is used for a work group that is involved in a training session with all members of the group present. The SNA can be completed prior to the training session and the results can be shared with the entire group at the beginning of the training program. A discussion on the potential barriers to transfer can occur, followed by strategies on how to overcome them and the best way to apply the new learning on the job. Although this adds to the length of the training program, addressing transfer issues up front will increase the likelihood of transfer actually occurring.

When conducting an SNA, the size of the organization must also be taken into consideration. A work group of just 10 people represents 90 unique relationships (directional), thus creating the potential for some relational issues. The size of the organization is irrelevant to the utility of SNA, but it must be considered from a methodological perspective. The number of respondents for a complete network analysis typically should not exceed 250 respondents, 


\section{TABLE 7: Sample: Ego Network Survey Completed Prior to Training}

Directions: Read below the three statements and think of the individuals you know at work and possibly in your personal life who would impact you. After listing their name, indicate their job role or relationship if the individual is not related to you through work. Then circle yes if that individual works in the same department as you. On a scale of 1 to 5, 1 being never and 5 being often, rate the individuals you listed for each of the following questions.

You can list as many individuals as you think relevant. If you require more space, simply turn the paper over and list them on the back of this page.

Q1: To get my work done I require the assistance of this individual.

Q2: After a training activity, I share the new knowledge I've acquired with this individual.

Q3: This individual has influence over how I get my job done.

\begin{tabular}{lccccc}
\hline Name of Individual & Role & Same Dept. & QI & Q2 & Q3 \\
\hline John & Supervisor & Y/N & 5 & 2 & 5 \\
Kim & Coworker & Y/N & 3 & 3 & 3 \\
Julie & Coworker & Y/N & 2 & 2 & 2 \\
Samantha & Coworker & Y/N & 2 & 3 & 2 \\
Liam & Manager & Y/N & 2 & 4 & 4 \\
Eric & Coworker & Y/N & 2 & 3 & 4 \\
Camryn & Manager & Y/N & 1 & 1 & 1 \\
Wendy & Coworker & Y/N & 5 & 5 & 2 \\
\hline
\end{tabular}

because the more the actors, the greater the difficulty in the data analysis (Cross \& Parker, 2004). If there are more than 250 actors, the ego network analysis can be conducted. Another option is to create a mixed method approach by conducting a complete network analysis for a work group, unit, or department and also provide the respondents the option of identifying additional individuals outside their work group. Individuals identified by the respondents outside the group can easily be identified by simply looking at the number of times the name was mentioned in the surveys.

\section{Conclusion}

SNA is tool that can assist both HRD researchers and practitioners by identifying the relational barriers to the transfer of new learning to the job. By identifying relational patterns within an organizational context, we can learn a lot about how training transfer occurs and the best ways to encourage a positive transfer climate. The transfer literature indicates that transfer climate is a major determinant of transfer. SNA can be used to develop strategies that may increase the likelihood of training transfer taking place. 


\section{References}

Baldwin, T. T., \& Ford, J. K. (1988). Transfer of training: A review and directions for future research. Personnel Psychology, 41, 63-105.

Bates, R. A., Holton, E. F., Seyler, D. L., \& Carvalho, M. A. (2000). The role of interpersonal factors in the application of computer-based training in an industrial setting. Human Resource Development International, 3, 19-42.

Borgatti, S. P. (2002). NetDraw: Graph visualization software. Harvard: Analytic Technologies.

Borgatti, S. P., Everett, M. G., \&Freeman, L. C. (2002). Ucinet for windows: Software for social network analysis. Needham, MA: Analytic Technologies.

Brass, D. J., \& Labianca, G. (Eds.). (1999). Social capital, the social ledger, and social resources management. Dordrecht, The Netherlands: Kluwer Academic.

Broad, M. L., \& Newstrom, J. W. (1992). Transfer of training: Action-packed strategies to ensure high payoff from training investments. Reading, MA: Addison-Wesley.

Burt, R. S. (1992). Structural holes: The social structure of competition. Cambridge, MA: Harvard University Press.

Burt, R. S. (1997). The contingent value of social capital. Administrative Science Quarterly, 42, 339-365.

Campbell, J. P. (1988). Training design for performance improvement. Productivity in Organizations. San Francisco: Jossey-Bass.

Cheng, E. W. L., \& Ho, D. C. K. (2001). A review of transfer studies in the past decade. Personnel Review, 30, 102-118.

Clark, C. S., Dobbins, G. H., \& Ladd, R. T. (1993). Exploratory field study of training motivation: Influence of involvement, credibility and transfer climate. Group and Organization Management, 18(3), 292-307.

Coleman, J. S. (1988). Social capital in the creation of human capital. American Journal of Sociology, 94, S95-S120.

Cromwell, S. E., \& Kolb, J. A. (2004). An examination of work-environment support factors affecting transfer of supervisory skills training to the workplace. Human Resource Development Quarterly, 15(4), 449-471.

Cross, R., \& Parker, A. (2004). The hidden power of social networks: Understanding how work really gets done in organizations. Boston: Harvard Business School Press.

Denison, D. R. (1996). What is the difference between organizational culture and organizational climate? A native's point of view on a decade of paradigm wars. Academy of Management Review, 21(3), 619-655.

Eagan, T. M., Yang, B., \& Bartlett, K. R. (2004). The effects of organizational learning culture and job satisfaction on motivation to transfer learning and turnover intention. Human Resources Development Quarterly, 15(3), 279-301.

Feeley, T. H., \& Barnett, G. A. (1996). Predicting employee turnover from communication networks. Human Communication Research, 23, 370-387.

Feld, S. L. (1997). Structural embeddedness and stability of interpersonal. Social Networks, 19, 91-95.

Georgenson, D. L. (1982). The problem of transfer calls for partnerships. Training and Development Journal, 36(10), 75-78.

Gist, M. E., Bavetta A. G., \& Stevens, C. K. (1990). Transfer training method. Personnel Psychology, 43, 501-523.

Goldstein, I. L. (1986). Training in organizations: Needs assessment, development, and evaluation. Monterey, CA: Brooks Cole.

Hatala, J. P. (2006). Social network analysis in human resource development: A new methodology. Human Resource Development Review, 5, 45-71. 
Hatala, J. P., \& Gumm, J. C. (2006). Managing organizational cultural influences during the implementation of competency-based training. Advances in Human Resource Development, 8(2), 229-246.

Holton, E. F. (1996). The flawed four-level model. Human Resource Development Quarterly, 7, $5-25$.

Holton, E. F., \& Baldwin, T. T. (2000). Making transfer happen: An action perspective on learning transfer systems. Advances in Developing Human Resources, 2(4), 1-6.

Holton, E. F., Bates, R. A., Seyler, D. L., \& Carvalho, M. B. (1997). Toward construct validation of a transfer climate instrument. Human Resource Development Quarterly, 8(2), 92-113.

Ibarra, H., \& Andrews, S. B. (1993). Power, social influence and sense making: Effects of network centrality and proximity on employee perceptions. Administrative Science Quarterly, 38, 277-303.

Kahn, W. A., Cross, R., \& Parker, A. (2003). Layers of diagnosis for planned relational change in organizations. Journal of Applied Behavioral Sciences, 39(3), 259-280.

Kim, H. (2004). Transfer of training as a sociopolitical process. Human Resource Development Quarterly, 15(4), 497-501.

Kontoghiorghes, C. (2002). Predicting motivation to learn and motivation to transfer learning back to the job in a service organization: A new systemic model for training effectiveness. Performance Improvement Quarterly, 15(3), 114-129.

Lim, D. H. (2001). The effect of work experience and job position on international learning transfer. International Journal of Vocational Education and Training, 9(2), 59-74.

Lim, D. H., \& Johnson, S. D. (2002). Trainee perceptions of factors that influence learning transfer. International Journal of Training and Development, 6, 36-48.

Lim, D. H., \& Morris, M. L. (2006). Influence of trainee characteristics, instructional satisfaction, and organizational climate on perceived learning and training transfer. Human Resource Development Quarterly, 17, 85-115.

Litwin, G., \& Stringer, R. (1968). Motivation and organizational climate. Cambridge, MA: Harvard University Press.

London, P. A., \& Flannery, D. D. (2004). Social factors that impact women's practice of breast self-examination: A challenge to the transfer of training literature. Journal of European Industrial Training, 28(6/7), 538-549.

Machles, D. (2002). Training transfer strategies for the safety professional. Safety Professional, 47(2), 32-34.

Meyer, G. W. (1994). Social information processing and social networks: A test of social influence mechanisms. Human Relations, 47, 1013-1048.

Morgan, D. L., Neal, M. B., \& Carder, P. (1996). The stability of core and peripheral networks over time. Social Networks, 19, 9-25.

Noe, R. A. (1988). Trainee's attributes and attitudes: Neglected influences on training effectiveness. Academy of Management Review, 11, 736-749.

Pidd, K. (2004). Organizational barriers to training transfer: The role of workplace social controls and normative behaviour in workplace development. National Center for Education and Training on Addiction.

Rossett, A. (1997). This was a great class, but..., Training and Development Journal, 51(7), 18-24.

Rouiller, J. Z., \& Goldstein, I. L. (1993). The relationship between organizational transfer climate and positive transfer in training. Human Resource Development Quarterly, 4, 377-390.

Scott, J. (2000). Social network analysis: A handbook (2nd ed.). London: Sage.

Suitor, J., \& Keeton, S. (1997). Once a friend, always a friend? Effects of homophily on women's support networks across a decade. Social Networks, 19, 51-62.

Taylor, M. C. (2000). Partners in the transfer of learning: A qualitative study of workplace literacy programs. Proceedings of the 41st Annual Adult Education Research Conference (pp. 459461). Vancouver: University of British Columbia.

Torenvlied, R., \& Velner, G. (1998). Informal networks and resistance to organizational change: The introduction of quality standards in a transport company. Computational \& Mathematical Organization Theory, 4(2), 165-188. 
Tracey, J. B., Tannenbaum, S. I., \& Kavanagh, M. J. (1995). Applying trained skills on the job: The importance of the work environment. Journal of Applied Psychology, 80(2), 239-252.

Wasserman, S., \& Faust, K. (1994). Social network analysis: Methods and applications. New York: Cambridge University Press.

Wellman, B., Wong, R., Tindall, D., \& Nazer, N. (1997). A decade of network change: Turnover, persistence and stability in personal communities. Social Networks, 19, 27-50.

White, D. R. (1997). What is network theory? Retrieved April 23, 2006, from http://eclectic.ss.uci .edu/drwhite/netsyl96.htm

John-Paul Hatala is assistant professor, Louisiana State University, Baton Rouge. His academic research has focused on the transition toward reemployment, social capital in the workplace, social networking behavior, and organizational development.

Pamela R. Fleming is a doctoral student in human resource and leadership development at Louisiana State University. Her research interest includes leadership, organization behavior, emotional intelligence, and training transfer. 